\title{
A Inclusão de Pessoas com Deficiência no Contexto do Trabalho em Florianópolis: Relato de Experiência no Sistema Nacional de Emprego
}

The Inclusion of People with Disabilities in the Job Market: Reporting an experience on National Employment Systems

La Inclusión de Personas con Discapacidad en el Lugar de Trabajo: un Informe Sobre la Experiencia en el Sistema Nacional de Empleo

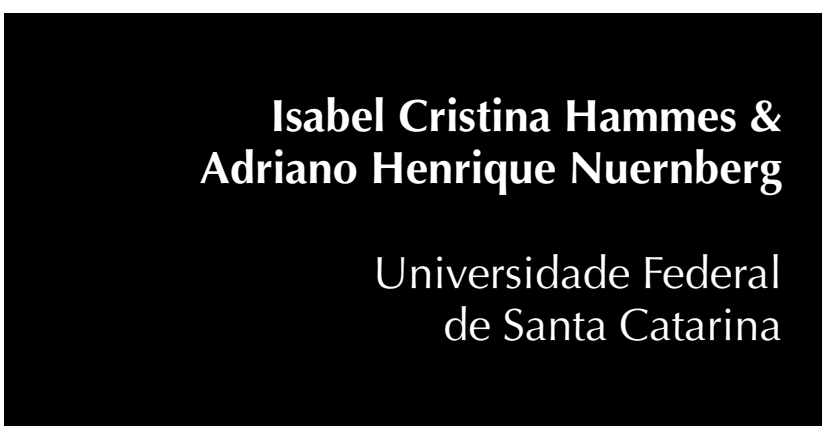

http://dx.doi.org/10.1590/1982-3703000212012 
Resumo: Após a implantação da Lei de Cotas, que obriga as empresas com mais de cem funcionários a contratarem pessoas com deficiência (PcD), percebeu-se uma mudança de paradigma que coaduna com o princípio de inclusão. Além disso, estudos de Responsabilidade Social Empresarial têm levantado a importância da diversidade dentro das organizações, apontando a inclusão das PcD como forte aliada para uma gestão socialmente responsável, com significativos ganhos para a empresa. Assim, este artigo pretende mostrar a experiência vivida pelo Sistema Nacional de Emprego (SINE), na Grande Florianópolis, por meio do desenvolvimento de ações específicas para inclusão das PcD no mundo do trabalho. Realizando atividades focadas no público interno, nos empregadores e trabalhadores com deficiência, o SINE teve um aumento de $52 \%$ no fluxo de atendimentos às PcD, intermediando a inserção desse público no mercado de trabalho. Constatou-se que as principais dificuldades encontradas no desenvolvimento dessas ações são as barreiras atitudinais, ou seja, o preconceito e o desconhecimento das pessoas acerca da deficiência, além da falta de rotina de fiscalização do cumprimento das cotas nas empresas e da presença de barreiras programáticas relativas ao BPC (Benefício da Prestação Continuada).

Palavras-chave: Pessoas com deficiência. Trabalho. Mercado de trabalho.

Abstract: After the implementation of the Quota Act, which requires companies with more than 100 employees to hire persons with disabilities (PWD), we noticed a paradigm shift consistent with the emergence of the principle of inclusion. Furthermore, studies on Corporate Social Responsibility have raised the importance of diversity within organizations, indicating the inclusion of PWD as strong allies for socially responsible management with significant gains for the company. Thus, this study aims to show the experience of Brazil's Sistema Nacional de Emprego, National Employment System (SINE) in Great Florianopolis regarding the development of specific actions for the inclusion of PWD in the job market. By implementing activities focused on the workforce, employers, and workers with disabilities, SINE registered a $52 \%$ increase in the number of services provided to PWD, mediating the inclusion of this population in the job market. However, it was found that the main difficulties encountered in developing such actions were attitudinal barriers, i.e., people's prejudice and ignorance about disabilities as well as a lack of routine monitoring of quota compliance in firms and the presence of barriers to the program Benefit from Continued Service (BPC).

Keywords: Disabled persons. Work. Job market.

Resumen:Después de la aplicación de la Ley de Cuotas, que obliga a las empresas con más de cien empleados a contratar a personas con discapacidad (PcD), se observa un cambio de paradigma que es consistente con la aparición del principio de inclusión. Adicionalmente, los estudios sobre la Responsabilidad Social Corporativa han planteado la importancia de la diversidad en las organizaciones, señalando la inclusión de la PcD como un fuerte aliado para la gestión socialmente responsable, con un incremento importante para la compañía. Por lo tanto, este artículo tiene como objetivo mostrar la experiencia vivida por el Sistema Nacional de Empleo (SINE), en Florianópolis, a través del desarrollo de acciones específicas para la inclusión de personas con discapacidad en el lugar de trabajo. Con la realización de actividades centradas en el público interno, en los empleadores y los trabajadores con discapacidad, el SINE tuvo un incremento del $52 \%$ en el flujo de atenciones a las PcD, mediando en la inserción de este público en el mercado laboral. Sin embargo, se encontró que las principales dificultades en el desarrollo de estas acciones son las barreras actitudinales, es decir, los prejuicios y el desconocimiento acerca de la discapacidad, así como, la falta de rutina de fiscalización del cumplimiento de las cuotas en las empresas y por la presencia de barreras relacionadas con el BPC (Beneficio Continuo de Servicio).

Palabras claves: Personas con discapacidad. Trabajo. Mercado de trabajo. 
1 Até agosto de 2015, momento de finalização desse artigo, não foram publicados os dados do IBGE sobre as causas da deficiência no Brasil segundo o Censo 2010.

\section{Introdução}

Ao refletir a respeito do lugar social das Pessoas com Deficiência (PcD) ao longo da história, é possível perceber na atualidade uma mudança de paradigma: a emergência do Princípio de Inclusão das PcD (Brasil, 2007; Brumer, Pavei, \& Mocelin, 2004; Gugel, 2009; Mazzotta, \& D’Antino, 2011). O tema começa a ser visto, debatido, aceito e respeitado em diversas esferas da sociedade, como no Judiciário, com as leis específicas para esse público, visando à acessibilidade e autonomia e ao enfrentamento dos preconceitos; na educação, com significativo aumento da matrícula de crianças com deficiência nas escolas comuns, e também no mundo do trabalho, principalmente após a criação, pelo Estado, de políticas afirmativas (Fonseca, 2006; Mendes, 2006). Assim, ainda que cercadas por diversas barreiras em sua participação na sociedade, as pessoas com deficiência têm vivenciado a melhoria das condições de sua inserção social.

A Lei de Cotas [art. 93 da Lei $\mathrm{n}^{\circ} 8.213 / 91$ (Brasil, 1991)], regulamentada pelo Decreto no 3.298 de 1999 (Brasil, 1999), que estabelece uma reserva de vagas às pessoas com deficiência proporcional ao tamanho da organização, é considerada um dos principais fatores para a promoção da inclusão social da pessoa com deficiência, pois, além de promover maior autonomia, inclusive financeira a essas pessoas, com importantes efeitos na sua autoestima, propiciou também aos demais funcionários o contato com a realidade dificuldades e potencialidades - das PcD, desmistificando-as. Conforme o Instituto Ethos (2002), trazer a diversidade para dentro da empresa é "promover a igualdade de chances para que todos possam desenvolver seus potenciais" (p. 11). Esse seria, então, o caminho para um desenvolvimento sustentável e inclusivo para toda a sociedade.

Segundo a Organização Mundial da Saúde (OMS), estima-se que exista cerca de um bilhão de pessoas com deficiência, representando $15 \%$ da população mundial (Organização Mundial da Saúde, 2012). Já no Brasil, no ano de 2010, conforme dados do Censo do Instituto Brasileiro de Geografia e Estatística (IBGE), havia cerca de 45 milhões de $\mathrm{PcD}$, ou seja, 23,9\% da população. Destes, 13 milhões são pessoas que apresentam graves deficiências, ou seja, que têm grande ou extrema dificuldade de ver, ouvir ou se locomover. Já segundo os dados anteriores do IBGE, do ano 2000, no tocante às causas das deficiências ${ }^{1}$, mais da metade delas (56,6\%) é adquirida ao longo da vida. Tomando esses dados de 2000 e analisando-os separadamente com relação às pessoas com deficiência física, esse índice aumenta para $77,7 \%$ devido principalmente a acidentes de trânsito ou causados por arma de fogo (Federação Brasileira de Bancos, 2006).

Quanto à inserção no mercado de trabalho, a pesquisa da Federação Brasileira de Bancos (FEBRABAN), no ano de 2006, mostra que, dentre as pessoas com deficiência entrevistadas, apenas $26,3 \%$ estavam trabalhando formalmente, sendo que a parcela mais beneficiada, até aquele momento, pela Lei de Cotas, era a dos deficientes auditivos. Esse fato se explica, uma vez que os deficientes auditivos não exigem adaptações físicas e nem tecnológicas, o que implica menor gasto para a empresa. Porém "os menos absorvidos são, justamente, pessoas com deficiência mental, que apresentam maiores dificuldades para alcançar escolarização compatível com as regras do mercado contemporâneo" (Lancillotti, 2003, p. 101).

A pesquisa da FEBRABAN (2006) aponta ainda que no ano de 2000 foram criadas cerca de 1.055 milhão de vagas através da política de cotas nas empresas com cem ou mais funcionários, aquecendo assim o mercado de trabalho para PcD. Porém, sabe-se que tais avanços ainda não são suficientes para garantir a inclusão dessas pessoas no trabalho. Tal fato é confirmado pelos dados oficiais da Relação Anual de Informações Sociais (Brasil, 2012) de 2010, a qual demonstra que, dos 44,1 milhões de trabalhadores formais, somente 306 mil são pessoas com deficiência, caracterizando apenas $0,7 \%$ do total de trabalhadores, um número bem aquém do esperado após vinte anos da aprovação da Lei de Cotas. 
É nesse contexto, de movimento pela inclusão da PcD no mundo do trabalho, que se dá este estudo, a partir das políticas vivenciadas no sistema público de empregos, na Grande Florianópolis, objetivando refletir acerca do papel deste sistema na efetividade da inclusão.

\section{Pessoas com deficiência e o mundo do trabalho}

O aquecimento no mercado de trabalho para pessoas com deficiência e sua recente inserção (na tentativa de uma plena inclusão) no mundo laboral, fomentaram a realização de diversos estudos na área (Araújo, \& Schmidt, 2006; Fonseca, 2006; Gugel, 2006; Simonelli, \& Camarotto, 2011). O tema é foco em estudos como os de Responsabilidade Social Empresarial, que apontam para a importância da diversidade nas organizações para uma gestão ética e transparente, o que inclui o respeito pelas pessoas, comunidades e meio ambiente (Lomônaco, 2012). Bahia e Santos (2009) mostram que, para as organizações modernas, ainda é um dos principais desafios lidar com a diversidade, valorizando a igualdade social nas diferenças de raça, etnia, orientação sexual e deficiência. Mas, "a partir do momento em que a contratação de pessoas vindas de minorias tornou-se inevitável, as empresas começam a incorporar a diversidade em suas práticas de gestão" (Bahia, \& Santos, 2009, p. 142).

O processo de inclusão das pessoas com deficiência nas empresas, segundo o Instituto Ethos (2002), traz ainda uma série de benefícios: (1) Sociais: as empresas têm uma grande capacidade de influenciar transformações sociais, possibilitando o resgate da cidadania dessas pessoas. Ou seja, há uma maior circulação das PcD na sociedade e, consequentemente, uma maior acessibilidade e autonomia das mesmas; (2) De imagem: as empresas beneficiam-se enormemente com ganhos de imagem com a contratação de pessoas com deficiência. Pesquisas mostram que, para grande parte das pessoas, essa ação seria a primeira que as estimularia a consumir mais produtos de determinada empresa; (3) Clima organizacional: a empresa inclusiva reforça em seus funcionários o espírito de equipe, que propicia a sinergia em torno de objetivos comuns. O espaço físico adequado também proporciona melhor qualidade de vida no trabalho para todos. Essas características sinalizam um ambiente de trabalho mais humano; (4) Aumento de produtividade: uma melhoria no clima organizacional e na qualidade de vida no trabalho podem proporcionar, consequentemente, um aumento de ganhos de produtividade, além de trazer para a empresa novas possibilidades de negócios. "O diverso traz para a empresa a possibilidade de ver novas oportunidades no seu negócio, além de prepará-la para demandas específicas de diferentes universos que incorpora" (Instituto Ethos, 2002, p. 19).

Estudos estrangeiros como o de Ondusko (1991) também apontam para uma diminuição do absenteísmo e rotatividade em empresas que contratam pessoas com deficiência e, do lado do empregado, Pereira, Del Prette e Del Prette (2008) apontam para a importância do trabalho na vida da pessoa com deficiência, quanto à maior valorização social e pessoal. Krumm (2005), reportando-se à experiência estadunidense, relata casos nos quais, a despeito do aumento dos custos, a presença de pessoas com deficiência na organização resultou em diversas melhorias, como a ampliação da descrição e análise dos cargos, a descoberta de novas soluções de produção e ganhos efetivos no clima organizacional da empresa.

Percebe-se, assim, a importância que o tema vem ganhando nas práticas de gestão atuais. Lidar com as diferenças e com a inclusão de minorias dentro da organização são temáticas essenciais no cotidiano empresarial. Para tanto, a tendência tem sido a superação da antiga prática do assistencialismo e protecionismo das pessoas com algum tipo de impedimento e/ou em condição de opressão social (Bahia, \& Santos, 2009). Segundo Bahia e Santos (2009), as empresas passam a buscar a inclusão, ensejando "ambientes de trabalho mais receptivos a trabalhadores tradicionalmente discriminados, estigmatizados ou marginalizados" (p. 146). Passam, deste modo, a contratar, manter e desenvolver pessoas com deficiência, reconhecendo suas potencialidades. 
No entanto, essa não é uma regra para todos os contextos organizacionais, uma vez que muitos resistem à presença de estagiários ou funcionários com deficiência por meio de justificativas que sustentam a impossibilidade da inclusão ou por meio de mecanismos legais que retardam esse processo. Conforme Ribeiro e Carneiro (2009), algumas empresas recorrem a argumentos como o do elevado grau de periculosidade de sua atividade para pessoas com deficiência e/ou a incompatibilidade da existência de impedimentos de natureza física, sensorial ou intelectual com as normas de segurança exigidas em Lei para determinados cargos e funções. Outras empresas, conforme esses autores, sustentam a inexistência de profissionais capacitados para o exercício das atividades funcionais da organização, como no caso das universidades que exigem para contratação de professores uma elevada titulação em uma área muito específica.

Nesse sentido, a efetiva inclusão das PcD no trabalho esbarra em três principais fatores: a) baixo nível de qualificação deste público, decorrente do processo histórico de segregação, o que propicia a contratação dessas pessoas principalmente para cargos da base da pirâmide empresarial; b) falta de acessibilidade nos transportes, edificações e espaços coletivos, que se tornam obstáculos por vezes intransponíveis; c) barreiras culturais, como o desconhecimento do potencial das pessoas com deficiência e o preconceito que, apesar de se encontrar em transformação, ainda é um forte impeditivo da inclusão efetiva (Bahia, \& Santos, 2009; Carvalho, 2009). Lancillotti (2003) complementa que a falta de informação dos empregadores sobre a capacidade produtiva das PcD é considerada um dos principais fatores responsáveis pela não absorção desses trabalhadores. Tal fato é observável a partir do senso comum, no qual existe a crença de que a pessoa com deficiência é incapacitada para as atividades laborais.

Carvalho (2009) ressalta que a inclusão não é uma ação, ou um conjunto de ações. É uma atitude, uma convicção, um modo de vida, que reflete a consciência da comunidade, de aceitação das diferenças; o que reforça a importância do aspecto cultural, de consciência coletiva, para uma real inclusão. O preconceito contra as pessoas com deficiência é tão marcante no processo de inclusão no mercado de trabalho que, na pesquisa de Carvalho (2009) realizada com pessoas com algum tipo de deficiência física, quase a totalidade $(97,4 \%)$ das pessoas entrevistadas percebe o preconceito como fator principal, o que contribui para aumentar as dificuldades para entrar no mercado de trabalho. O mesmo dado é corroborado pela pesquisa de Almeida, Carvalho-Freitas e Marques (2008), na qual PcD entrevistadas tendem a concordar que, por possuírem alguma deficiência, já perderam oportunidades de emprego.

Apesar das dificuldades, Carvalho (2009) afirma que a ocupação profissional é essencial para uma efetiva inclusão, não só por fatores econômicos, mas também como uma forma de convívio e integração social. Almeida et al. (2008) complementam que o trabalho, principalmente o associado a um emprego, é um importante fator na diminuição das taxas de pobreza desse público (já que 29\% encontram-se em situação de miséria) e na diminuição do isolamento social, melhorando a sua autoestima por se sentirem cidadãos completos, respeitados e reconhecidos socialmente, independentemente de suas limitações. O trabalho para a PcD representa, então, "uma dimensão interdependente da percepção que tem de si mesma e da própria vida" (Almeida et al., 2008, p. 56).

\section{Método: o sistema público de empregos e o atendimento à pessoa com deficiência no SINE/SC}

O sistema público de empregos no Brasil é representado, atualmente, pelo Sistema Nacional de Emprego (SINE), criado em 1975 com o objetivo inicial de promover a intermediação de mão de obra, caracterizando uma agência de empregos pública e gratuita. Hoje o SINE oferece também apoio operacional ao pagamento do benefício do seguro-desemprego, qualificação 
profissional e geração de informações sobre o mercado de trabalho. Sua rede de postos de atendimento ao trabalhador se estende por milhares de cidades em todo o país (Brasil, 2011a; 2015a).

Atualmente, no estado de Santa Catarina, são 105 postos, sendo 22 administrados diretamente pelo governo do estado e os demais em parceria com as prefeituras municipais; representam, assim, o maior banco de dados entre trabalhadores e empregadores de SC. Somente no ano de 2010, foram (re)colocados no mercado de trabalho mais de 33 mil trabalhadores através do SINE, o que demonstra o importante papel econômico e social do referido serviço. (Brasil, 2011a)

No mesmo ano, implantou-se o Serviço de Atendimento Psicossocial em 18 cidades catarinenses, com o objetivo de aumentar a colocação de trabalhadores no mercado de trabalho, facilitando a intermediação destes com as vagas, principalmente com o público que apresenta dificuldades de inserção no mundo laboral (idosos, primeiro-emprego, pessoas com deficiência, reabilitados do INSS, pessoas em situação de vulnerabilidade social, etc.). A primeira autora deste texto foi uma das profissionais admitidas, corresponsável (juntamente com a assistente social) pelo Serviço na cidade de Florianópolis. No que se refere aos trabalhadores com deficiência, esse setor foi responsável pela elaboração do Projeto de Inclusão das Pessoas com Deficiência no Mercado, que consistiu nas seguintes etapas:

Criação de uma rede de discussão acerca da temática junto a outras instituições

Para uma inclusão efetiva das pessoas com deficiência no mundo laboral, era essencial a discussão da temática junto a diversos atores sociais envolvidos no processo, a fim de que se obtivesse uma posterior definição de papéis no fluxo de atendimento. Tal discussão tornou-se primordial, principalmente após a Superintendência Regional do Trabalho e Emprego (SRTE/SC) dar início ao trabalho de fiscalização das empresas, para avaliar o cumprimento das cotas para PcD. Segundo levantamento feito junto aos profissionais desse órgão, a sistematização da fiscalização nunca havia acontecido no Estado, sendo este um fato histórico na região. Assim, sem o controle do órgão fiscalizador, era comum o não cumprimento das cotas, razão pela qual era mais difícil a entrada de pessoas com deficiência no mercado de trabalho. Tal fato é expresso no baixo índice de contratação desses trabalhadores em Santa Catarina - 0,7\% do número total de contratados, segundo dados fornecidos pelo SINE em 2010.

Com o início das ações da SRTE/SC na região da Grande Florianópolis, ocorreu uma maior abertura no mercado de trabalho para $\mathrm{PcD}$ e, consequentemente, um grande aumento da demanda desse público no SINE. Centenas de empresas passaram a cadastrar vagas e demandar mais profissionais, diante da pressão da SRTE. Somente no mês de novembro (2010), aproximadamente três meses após o início da fiscalização, houve um recorde de vagas cadastradas no SINE para esse público, totalizando mais de 500, somente na Grande Florianópolis.

Assim, com a intensificação da demanda, buscaram-se parcerias para a criação de políticas voltadas ao público de PcD dentro das ações do SINE. Para isso, surgiu uma rede de discussão sobre a inclusão, no trabalho, da pessoa com deficiência, junto às instituições que atendem esse público, bem como representantes da Superintendência Regional do Trabalho e Emprego e do Instituto Nacional do Seguro Social (INSS), além de instituições de ensino e outros órgãos envolvidos na temática. Essa rede possibilitou: (1) a troca de apoio entre órgãos; (2) reflexões acerca das dificuldades da inclusão desse público no mercado e as possibilidades de superação das mesmas; (3) a divisão de responsabilidades de cada instituição no que diz respeito ao processo de inclusão das PcD; (4) a elaboração de atividades de sensibilização e orientação de empregadores de pessoas com deficiência, bem como a criação de materiais informativos a serem divulgados ao público em geral. 
Definição do papel do SINE e dos demais atores sociais envolvidos

Após a criação da rede de discussão com os demais atores sociais, entendeu-se como responsabilidade do sistema público de empregos a concentração da captação de vagas para $\mathrm{PcD}$, bem como o encaminhamento dessas pessoas às empresas. Este trabalho vai ao encontro do artigo 27 da Convenção Sobre os Direitos das Pessoas com Deficiência, que prevê como responsabilidade do Estado "promover oportunidade de emprego e ascensão profissional para pessoas com deficiência no mercado de trabalho, bem como assistência na procura, obtenção e manutenção do emprego e no retorno ao emprego" (Brasil, 2007, p. 31).

O trabalho realizado pelo SINE foi então revisto, sendo que o Serviço de Atendimento Psicossocial desempenhou papel fundamental na estruturação desse trabalho, tendo duas frentes: o empregador de PcD, que em geral não estava acostumado a trabalhar com esse público e acabou por provocar grandes demandas, e o público com deficiência que, devido à realidade em que estava inserido, pouco frequentava as dependências do local.

Capacitação dos servidores do SINE para $o$ atendimento a pessoas com deficiência

Para proporcionar atendimento aos trabalhadores com deficiência, as profissionais Psicóloga e Assistente Social buscaram formação complementar visando oferecer um atendimento especializado, bem como orientar e oferecer suporte à equipe de atendentes responsáveis pelo atendimento de PcD, e de empresas contratantes desse público. Com o aquecimento na procura de vagas, tornou-se imprescindível a sensibilização e o treinamento desses funcionários, principalmente para desmistificar a deficiência e qualificá-los para o atendimento livre de barreiras atitudinais que historicamente marcam esse público.

\section{Sensibilização das empresas}

No que se refere aos empregadores de pessoas com deficiência, constatou-se que grande parte tinha algum tipo de preconceito ou desconhecimento acerca das potencialidades das PcD. Muitas empresas claramente importavam-se somente em atender as condições impostas pela SRTE, recebendo "qualquer profissional", desde que o mesmo apresentasse deficiência; ou então, somente eram oferecidas vagas com pouca exigência de escolaridade e com baixíssimos salários, como os relativos às atividades de limpeza. Outras empresas, ainda, somente disponibilizavam vagas com rigorosas especificidades, de difícil preenchimento, e sem flexibilização das mesmas. Supõe-se que esta seja uma forma de demonstrar à fiscalização a tentativa de cumprimento da cota, alegando falta de profissionais no mercado que se ajustassem ao perfil destas empresas. Constatou-se, portanto, que empresas com esse perfil não estavam prontas para a inclusão de pessoas com deficiência em seu quadro profissional.

Diante desse cenário, o trabalho do setor responsável foi o de conscientizar as empresas sobre o papel social da contratação responsável das pessoas com deficiência - e não somente o cumprimento de cotas -, bem como de sensibilizá-las para que ampliassem seu olhar para a contratação desse público. Além disso, foram disponibilizados serviços de instituições parceiras, que oferecem consultorias especializadas na inclusão das PcD nas empresas, para que as orientassem nesse processo. Após esse primeiro contato, com grande enfoque em desmistificar a deficiência e apresentar as potencialidades das PcD, obteve-se boa resposta das empresas no que diz respeito à flexibilização de vagas (quando as empresas permitiam receber candidatos para os quais inicialmente não se mostravam abertas a empregar), ampliando assim a possibilidade de contratação do trabalhador.

Atendimento e encaminhamento dos trabalhadores com deficiência ao mercado de trabalho

Por meio dos constantes encaminhamentos das instituições parceiras, obteve-se um significativo aumento na demanda de trabalhadores com deficiência. Nesse processo, desempenhou um papel fundamental a 
divulgação frequente de vagas disponíveis no SINE para as instituições participantes da rede de discussão. Além disso, fez-se necessária a chamada de candidatos em mídia televisiva, para atingir diferentes públicos, além dos já comuns às instituições de atendimento específico às $\mathrm{PcD}$, atingindo-se um bom nível de alcance.

Ao chegar ao SINE, os trabalhadores com deficiência foram atendidos pelas profissionais do Serviço de Atendimento Psicossocial (preferencialmente), que realizavam o cadastro do perfil do profissional no sistema da instituição, possibilitando o cruzamento de dados com o perfil solicitado pelas empresas. Ao ser encontrada uma oportunidade de emprego, o candidato era encaminhado para a empresa para uma entrevista de emprego. Além desse cadastro, foram preenchidos também formulários específicos desse setor, com informações mais detalhadas do profissional, permitindo assim uma busca posterior dessas pessoas, caso surgissem novas oportunidades. Também foram fornecidas orientações acerca do mercado de trabalho, como por exemplo a documentação necessária exigida e comportamentos durante entrevistas de emprego, bem como encaminhamentos - quando necessário - para a rede socioassistencial.

\section{Limitações, possibilidades e resultados}

Cumpre notar que, no desenvolvimento de ações voltadas para o público com deficiênica no sistema público de empregos, algumas limitações e dificuldades foram percebidas, sendo uma das principais a falta de conhecimento e o preconceito acerca dessa condição, que se reflete no trabalho com todos os atores envolvidos.

Pode-se citar como exemplo o constante trabalho de sensibilização, orientação e conscientização com os funcionários do SINE, visando à superação de mitos relacionados às $P_{C D}$, principalmente quanto às dificuldades de comunicação, bem como à realização de certas atividades. A orientação aos atendentes buscou ajudá-los a superar as dificuldades que enfrentam no atendimento à pessoa com deficiência, facilitando o relacionamento entre atendente e PcD, a fim de diminuir a distância construída pelo preconceito e a falta de conhecimento, melhorando assim a eficiência do trabalho.

Os entraves são percebidos também com as pessoas com deficiência (e principalmente as suas famílias) as quais, por vezes, não se consideram capazes e autônomas para desenvolver certas atividades dentro de seu potencial laboral. Esse processo, contudo, não deve ser considerado como uma justificativa para a não inclusão, o que levaria a um processo de revitimização, uma vez que sua origem está na exclusão e no descrédito social a que essas pessoas foram historicamente submetidas. Ao contrário, justamente com a inclusão e com o suporte social, essas pessoas passarão a ressignificar suas experiências, superando essas formas de vulnerabilidade social.

A visão generalista nas empresas (percepção de deficiência somente como cadeirante ou cego total, por exemplo) é evidente na cotidiana dificuldade de flexibilização no oferecimento de vagas. Muitas vezes, apenas o trabalho de conscientização não é o suficiente para que o empregador seja receptivo ao trabalhador com deficiência. Essas questões culturais ainda representam um forte peso nas políticas de Gestão de Pessoas, o que faz com que a contratação de pessoas com deficiência ainda não seja um processo natural dentro das organizações.

Percebe-se claramente um grande despreparo nas políticas organizacionais - e dos trabalhadores de $\mathrm{RH}$ - para lidar com os trabalhadores com deficiência. Uma das consequências dessa cultura é o fluxo de vagas abertas no SINE para PcD, que é diretamente proporcional à intensificação da fiscalização da SRTE. Nesses períodos, tem-se um "inchaço" de vagas e uma procura acirrada por profissionais. Ao se abrandar a fiscalização, o número de vagas decai bruscamente, chegando próximo a zero, sendo essa uma grande dificuldade para efetivar a inclusão pretendida. 
Outro obstáculo, vivenciado no trabalho do sistema público de empregos e apontado por demais autores (Almeida et al., 2008; Bahia, \& Santos, 2009) foi o Benefício de Prestação Continuada (BPC) enquanto regulado pela Lei ${ }^{\circ}$ 8.742/1993 (Brasil, 1993), ou seja, até 2011. Este benefício faz parte da política nacional de seguridade social e garante a proteção às necessidades individuais básicas à parcela extremamente pobre da população idosa e aos deficientes com maior comprometimento social (Diniz, Medeiros, \& Barbosa, 2010). Segundo dados da Secretaria de Estado da Assistência Social, Trabalho e Habitação de Santa Catarina, mais de 3.750.000 pessoas recebem o BPC no país, sendo que, destes, 2.035 .969 são pessoas com deficiência, o que mostra a importância desse programa de transferência de renda no Brasil.

Tal benefício vinha sendo considerado bastante controverso, pois, da forma como estava regulamentado, não somente assegurava os direitos de milhões de pessoas com deficiência, mas também, no âmbito do trabalho, era visto como uma forte barreira para a entrada dessas pessoas no mercado, uma vez que tendia a promover um sentimento de insegurança e instabilidade diante da possibilidade de ingresso no mercado de trabalho (Almeida et al., 2008).

Assim, até meados de 2011, o BPC poderia ser visto como uma barreira programática ${ }^{2}$ à inclusão, no trabalho, das pessoas com deficiência. Uma vez que grande parte das vagas ofertadas para PcD são de baixa remuneração, recebendo o equivalente a aproximadamente um salário-mínimo, tornava-se pouco atrativo para grande parte dessas pessoas - e suas famílias - arriscar-se a perder esse benefício, tendo em vista a instabilidade de um emprego formal. Por esse motivo, muitas dessas pessoas trabalhavam informalmente para complementar a renda.

No entanto, com a promulgação da Lei $\mathrm{n}^{\circ}$ 13.146, de 6 de julho de 2015 (Brasil, 2015b), tornou-se possível que a pessoa com deficiência passe a ser beneficiada com o auxílio-inclusão ao exercer atividade remunerada que a enquadre como segurado obrigatório do Regime Geral da Previdência Social (RGPS).

Ainda que exista grande desconfiança quanto ao impacto prático e social desta Lei, que exige dos mecanismos de controle social um acompanhamento efetivo, espera-se que essa recente medida implique um aumento da inclusão das pessoas com deficiência no mercado de trabalho, uma vez que com a garantia de terem suporte do auxílio-inclusão em caso de desemprego, muitas podem, assim, ter a segurança necessária para lançarem-se ao mercado de trabalho ou entrarem na formalidade por meio de contratos de trabalho regidos pela Lei. Essa medida é considerada um avanço no que se refere às garantias de direitos das pessoas com deficiência e pode trazer significativas mudanças no mercado de trabalho para esse público, além de promover sua dignidade e equidade.

Apesar dessas limitações e dificuldades de implementação de ações no sistema público de empregos voltadas para as pessoas com deficiência no período em que se realizou este estudo, consideramos que o resultado do trabalho foi positivo. Obteve-se, nesse início, um aumento de $43 \%$ em novas inscrições nas bases de dados do SINE (comparando-se o primeiro e o segundo semestre de 2010) e um aumento de $52 \%$ no fluxo de atendimentos a esse público na Grande Florianópolis. Apesar de não ter sido possível o levantamento de dados precisos sobre a contratação das PcD encaminhadas através do SINE para o mercado de trabalho, consideramos que o órgão teve grande participação no processo de contratação das 285 pessoas com deficiência (conforme dados divulgados pela SRTE/SC), na Grande Florianópolis, no período de agosto a dezembro de 2010.

\section{Considerações finais}

Os profissionais que atuam nos contextos de gestão de recursos humanos deparam-se com a necessidade de reavaliar seus processos e instrumentos, visando a perspectiva da diversidade e inclusão que emerge diante dessa 
3 Agradecemos aos revisores anônimos pelas valiosas contribuições registradas nos pareceres enviados pelo comitê editorial. realidade. Para além de um processo restrito à atenção ao disposto na Lei, a inclusão das pessoas com deficiência representa, ao mesmo tempo, um desafio e uma oportunidade de incremento dos processos, atividades, fluxos e relações de trabalho.

Cabe a esses profissionais a tarefa de atuar não apenas no processo de seleção e recrutamento das pessoas com deficiência, mas também no acompanhamento efetivo de sua inserção e na promoção das mudanças culturais e organizacionais que demandam a presença das pessoas com deficiência nos ambientes de trabalho, considerando o histórico de segregação que marca esse grupo social, sobretudo no tocante às pessoas com deficiências sensoriais e intelectuais. Nesse sentido, a criação de programas específicos para a promoção de uma cultura inclusiva que envolva toda a organização pode ser um caminho interessante, especialmente se garantir a participação dos funcionários com deficiência, valorizando sua experiência pessoal e profissional.

O desenvolvimento de políticas públicas para as pessoas com deficiência é propulsionador de transformação social. A inclusão das pessoas com deficiência no contexto do trabalho e da escola vem sendo considerada primordial nesse processo e já traz hoje reflexos no convívio social, num processo que tende ao resgate da cidadania e respeito pelos direitos de todas as pessoas.

O desenvolvimento das políticas públicas para as pessoas com deficiência, no âmbito do serviço público de empregos, demonstra que, a despeito das limitações já apontadas, o Estado vem buscando fazer sua parte, num início tardio, para olhar a questão da inclusão das pessoas com deficiência. Entretanto, consideramos que ainda há muito para ser feito em prol da efetividade dos direitos garantidos pela Convenção pelos Direitos da Pessoa com Deficiência, como a proibição da discriminação, a garantia de acesso a programas de qualificação e assistência na manutenção do emprego.

Para a efetivação das demais competências do Estado, e consequentemente para a criação de novas políticas públicas para esse setor da população, os bancos de dados de serviços públicos, como o SINE - que possui um cadastro completo acerca da situação econômica, social, grau de escolaridade e formação, bem como condições de trabalho -, poderiam ser melhor utilizados para promoção dos direitos de acesso ao trabalho e renda das pessoas com deficiência ${ }^{3}$. 


\section{Isabel Cristina Hammes}

Graduada em Psicologia pela Universidade Federal de Santa Catarina. Florianópois - SC. Brasil.

E-mail: isabel.hammes@gmail.com

\section{Adriano Henrique Nuernberg}

Doutor pela Universidade Federal de Santa Catarina. Florianópois - SC. Brasil. Docente da Universidade Federal de Santa Catarina. Florianópois - SC. Brasil.

E-mail: adriano.nuernberg@ufsc.br

\section{Endereço para envio de correspondência:}

Centro de Filosofia e Ciências Humanas

Universidade Federal de Santa Catarina - UFSC

Campus Universitário - Trindade. CEP: 88.040-970. Florianópolis - SC. Brasil.

Recebido: 07/02/2012, $1^{\text {a }}$ Reformulação:12/02/2014, Aprovado: 03/07/2015. 
Almeida, L. A. D., Carvalho-Freitas, M. N., \& Marques, A. L. (2008). Análise comparativa das percepções das pessoas com deficiência em relação à inserção no mercado formal de trabalho. In M. N. Carvalho-Freitas, \& A. L. Marques (Orgs.),Trabalho e pessoas com deficiência: pesquisas, práticas e instrumentos de diagnóstico (pp. 55-70). Curitiba, PR: Juruá.

Araujo, J. P.; Schmidt, A. (2006). A inclusão de pessoas com necessidades especiais no trabalho: a visão de empresas e de instituições educacionais especiais na cidade de Curitiba. Revista Brasileira de Educação Especial, 12(2), 241-254. doi:10.1590/S1413-65382006000200007

Bahia, M. S., \& Santos, E. M. (2009). Práticas empresariais para a inclusão profissional de pessoas com deficiência: um estudo de caso.. In M. N. Carvalho-Freitas, \& A. L. Marques (Orgs.),Trabalho e pessoas com deficiência: pesquisas, práticas e instrumentos de diagnóstico (pp. 142-160). Curitiba, PR: Juruá.

Brasil (1999). Decreto n. 3.298, de 20 de dezembro de 1999. Regulamenta a Lei 7.853, de 24.10.1989, que dispõe sobre a Política Nacional para a Integração da Pessoa Portadora de Deficiência, consolida as normas de proteção, e dá outras providências. Diário Oficial da Brasília, DF. 21 de dezembro de 1999.

Brasil (1991). Lei n. 8.213, de 24 de julho de 1991. Dispõe sobre os Planos de Benefícios da Previdência Social e dá outras providências. Diário Oficial da Brasília, DF. 25 jul. 1991.

Brasil (1993). Lei $\mathrm{n}^{\circ}$ 8.742, de 7 de dezembro de 1993. Dispõe sobre a organização da Assistência Social e dá outras providências. Diário Oficial da Brasília, DF. 8 de dezembro de 1993.

Brasil. (2015b). Lei no 13.146, de 6 de julho de 2015. Institui a Lei Brasileira de Inclusão da Pessoa com Deficiência (Estatudo da Pessoa com Deficiência). Diário Oficial da União, Brasília, DF, 7 de julho de 2015.

Brasil (2011a), Ministério do Trabalho e Emprego. O que é o SINE. Recuperado em 16 de agosto de 2011, http://www.mte.gov. $\mathrm{br} / \mathrm{sine} /$ oquee.asp
Brasil (2012), Ministério do Trabalho e Emprego. Características do Emprego Formal segundo a Relação Anual de Informações Sociais (RAIS). Recuperado em 10 de janeiro de 2012, de http://www.mte.gov.br/rais/2010/ arquivos/Resultados_Definitivos.pdf

Brasil, Ministério do Trabalho e Emprego. (2015). Sistema Nacional de Emprego. Recuperado em 10 de agosto de 2015, de http://portal. mte.gov.br/sine/postos-do-sine/uf/sc.htm

Brasil. (2007), Secretaria Especial dos Direitos Humanos. Convenção sobre os Direitos das Pessoas com Deficiência: Protocolo Facultativo à Convenção sobre os Direitos das Pessoas com Deficiência. Brasília, DF: o autor.

Brumer, A., Pavei, K., \& Mocelin, D. G. (2004). Saindo da "escuridão": perspectivas da inclusão social, econômica, cultural e política dos portadores de deficiência visual em Porto Alegre. Sociologias, (11), 300-327. doi:10.1590/S1517-45222004000100013

Carvalho, K. M. (2009) Os desafios da inclusão da pessoa com deficiência no ambiente de trabalho. In M. N. Carvalho-Freitas, \& A. L. Marques (Orgs.),Trabalho e pessoas com deficiência: pesquisas, práticas e instrumentos de diagnóstico (pp. 43-54). Curitiba, PR: Juruá.

Diniz, D., Medeiros, M., \& Barbosa, L. (2010). Deficiência e igualdade. Brasília, DF: Letras Livres.

Federação Brasileira de Bancos - Febraban. (2006). População com deficiência no Brasil: fatos e percepções. São Paulo, SP: o autor.

Fonseca, R. T. M. (2006) O trabalho da pessoa com deficiência e a lapidação dos direitos humanos: o direito do trabalho, uma ação afirmativa. São Paulo, SP: LTr.

Gugel, M. A. (2009) Pessoas com deficiência e o direito ao trabalho. Florianópolis, SC: Obra Jurídica.

Instituto Brasileira de Geografia e Estatística - IBGE (2000).Censodemográficode2000.Recuperado em 22 de maio de 2011, de www.ibge.gov.br

Instituto Ethos. (2002). O que as empresas podem fazer pela inclusão das pessoas com deficiência. São Paulo, SP: o autor. 
Krumm, D. (2005) Psicologia do trabalho: uma introduçãoàpsicologiaindustrial/organizacional. Rio de Janeiro, RJ: LTC.

Lancillotti, S. S. P. (2003). Deficiência e trabalho. Campinas, SP: Autores Associados.

Lomônaco,J.F.(2012)Conceitoderesponsabilidade social de gestores e empregados. Psicologia: Ciência e Profissão 32(1). doi:10.1590/S1414-98932012000100016

Mazzotta, M. J. S., \& D'Antino, M. E. F. (2011). Inclusão social de pessoas com deficiências e necessidades especiais: cultura, educação e lazer. Saúde e Sociedade, 20(2), 377-389. doi:10.1590/S0104-12902011000200010.

Mendes, E. G. (2006). A radicalização do debate sobre inclusão escolar no Brasil. Revista Brasileira de Educação, 11(33), 387-405. doi:10.1590/S1413-24782006000300002.

Ondusko, D. (1991). Comparison of employees with disabilities and able-bodied workers in janitorial maintenance. Journal of Applied Rehabilitation Counseling, 22(2), 19-24.

Organização Mundial de Saúde (2011). Relatório mundial sobre a deficiência: sumário. São Paulo, SP: Governo do Estado de São Paulo.

Pereira, C. S., Del Prette, A., \& Del Prette, Z. A. (2008) Qual o significado do trabalho para as pessoas com e sem deficiência física? PsicoUSF, 13(1), 105-114. doi:10.1590/S1413-82712008000100013

Ribeiro, M. A.; \& Carneiro, R. (2009). A inclusão indesejada: as empresas brasileiras face à Lei de Cotas para pessoas com deficiência no mercado de trabalho. Organizações \& Sociedade, 16(50), 545-564. doi:10.1590/ S1984-92302009000300008

Santos, L. (2009). Perfil do mercado de trabalho para pessoas com deficiência: dados RAIS 2009. Recuperado em 8 de dezembro de 2010, de http://www.sine.sc.gov.br

Simonelli, A. P., \& Camarotto, J. A. (2011). Análise de atividades para a inclusão de pessoas com deficiência no trabalho: uma proposta de modelo. Gestão \& Produção, 18(1), 13-26. doi:10.1590/S0104-530X2011000100002

Vivarta, V. (Coord.). (2003). Mídia e deficiência (Diversidade, vol. 2). São Paulo: Agência de Notícias dos Direitos da Infância. 